\title{
Comportamento de Andropogon gayanus cv. 'planaltina' e Panicum maximum cv. 'tanzânia' sob sombreamento
}

\author{
Performance of Andropogon gayanus and Panicum maximum cv. 'Tanzania' in the shading
}

\author{
Fabiana Lopes Ramos de Oliveira ${ }^{\mathrm{I}^{*}}$ Verônica Alves Mota ${ }^{\mathrm{I}}$ Maira Soares Ramos ${ }^{\mathrm{II}}$ \\ Leonardo David Tuffi Santos ${ }^{\text {II }}$ Neide Judith Faria de Oliveira ${ }^{\text {II }}$ Luciana Castro Geraseev $^{\text {II }}$
}

RESUMO

A utilização de forrageiras tolerantes ao sombreamento é fundamental para a sustentabilidade da integração lavoura-pecuária-floresta. Estudou-se o comportamento do Panicum maximum cv. 'Tanzânia' e do Andropogon gayanus $c v$. 'Planaltina' sob diferentes níveis de sombreamentos e épocas de entrada sob a sombra. Utilizou-se delineamento em blocos casualizados, com quatro repetições, em esquema fatorial com dois tipos de sombreamento: $30 \%$ e $50 \%$; três épocas de entrada na sombra após transplante $(07$, 14 e 21 dias); e uma testemunha, mantida a pleno sol. Mudas com 8 a $12 \mathrm{~cm}$ de altura das duas espécies, pré-cultivadas em bandejas de isopor, foram transplantadas para vasos e mantidas nos respectivos ambientes sombreados ou a pleno sol por 90 dias, em livre crescimento. A época de entrada na sombra não interferiu na produtividade e nos teores de clorofila foliar das cultivares, assim como na composição bromatológica. As massas seca e fresca das cultivares 'Tanzânia' e 'Planaltina' foram superiores em ambientes sombreados, quando comparadas ao pleno sol. As duas forrageiras, quando sombreadas, incrementaram os teores de clorofila a, porém não se observou alteração para clorofila $b$. A adaptação positiva em ambientes sombreados das cultivares torna-se promissora em sistemas de integração silvipastoris.

Palavras-chave: adaptação ecológica, ecofisiologia.

\footnotetext{
ABSTRACT

The use of grasses tolerant to shade is essential to the sustainability of the Farming-Livestock-Forest Integration System. The performance of Panicum maximum cv. 'Tanzania' and Andropogon gayanus cv. 'Planaltina' under different levels of shading and times of entry under the shade were studied. We used designs in randomized blocks with four replications in a
}

factorial scheme with two types of shading: $30 \%$ and 50\%; three times of entry into the shade after transplantation $(07,14$ and 21 days) and a witness, kept in full sun. Seedlings 8 to $12 \mathrm{~cm}$ high of both species, pre-cultivated in styrofoam trays were transplanted to pots and maintained in their respective environments under the shade or full sun for 90 days in normal growth. The time of entry into the shade does not interfere with productivity and leaf chlorophyll content of cultivars, as well as in the bromatological composition. The fresh and dry matter of the cultivars of both 'Planaltina' and 'Tanzania' were higher in shaded environments rather than those in full sun. The two forage grasses when shaded increase the chlorophyll a content, but no change of chlorophyll $b$ was thereof observed. The positive adaptation of cultivars in the shaded environments becomes promising in systems of integration of pastures with trees.

Key words: ecological adaptation, ecophysiology.

\section{INTRODUÇÃO}

$\mathrm{O}$ interesse em estabelecer pastagens com forrageiras sombreadas tem crescido nos últimos anos, em virtude das associações dos sistemas de produção com culturas anuais e espécies arbóreas na integração lavoura-pecuária-floresta (ILPF). Desse modo, a adaptação de forrageiras às condições de sombreamento é especialmente relevante nas regiões com regime pluviométrico irregular, pois, em ambientes sombreados, o solo retém maior umidade e apresenta menor evapotranspiração (CAMPOS et al., 2007).

'Programa de Pós-graduação em Ciências Agrárias, Instituto de Ciências Agrárias (ICA), Universidade Federal de Minas Gerais (UFMG), 96201-900, Montes Claros, MG, Brasil. E-mail: fabianalro@gmail.com. *Autor para correspondência.

"ICA, UFMG, Montes Claros, MG, Brasil. 
Observações de campo reforçam esse fato, indicando que o pasto se mantém verde por mais tempo sob a copa de árvores, quando comparado ao pleno sol, fato observado principalmente em situações de estresse hídrico prolongado (PACIULLO et al., 2011). Estudos relacionados às características morfofisiológicas das forrageiras sombreadas são relevantes para entender melhor a resposta dessas espécies e preencher lacunas da literatura quanto ao assunto.

A adaptação das plantas forrageiras à variação da intensidade luminosa está ligada a modificações morfofisiológicas (DIAS-FILHO, 2000). Gramíneas, quando sombreadas, apresentam folhas com largura reduzida, células menos compactadas, em menor número, tamanho e volume, bem como uma taxa fotossintética inferior à observada em plantas mantidas a pleno sol (CASTRO et al., 1999).

A produtividade e a persistência de forrageiras cultivadas sob árvores podem ser influenciadas diretamente pelo efeito do sombreamento, podendo interferir no crescimento e no desenvolvimento da parte aérea e especialmente das raízes, havendo decréscimo de ambas quando os níveis de radiação são inadequados, com reflexos na redução da taxa fotossintética e na absorção de nutrientes (GUENNI et al., 2008).

Dentre as gramíneas recomendadas para cultivos sob sombreamento, estão o Andropogon gayanus e o Panicum maximum (ANDRADE, 1994; MACEDO \& ZIMMER, 2007). No Norte de Minas Gerais, essas gramíneas são as mais trabalhadas, por causa da sua tolerância às condições edafoclimáticas da região e pelos sistemas de produção instalados, sobretudo pela pecuária extensiva de corte, em sua maioria, e de leite. Objetivou-se estudar o comportamento de $\boldsymbol{A}$. gayanus cv. 'Planaltina' e $\boldsymbol{P}$. maximum cv. 'Tanzânia' sob diferentes níveis de sombreamento.

\section{MATERIAL E MÉTODOS}

Foram realizados dois experimentos: um com capim andropógon (Andropogon gayanus cv. 'Planaltina') e outro com capim 'Tanzânia' (Panicum maximum cv. 'Tanzânia'), conduzidos simultaneamente na casa de vegetação, pertencente à Fazenda Experimental Professor Hamilton de Abreu Navarro do Instituto de Ciências Agrárias- UFMG, Montes Claros-MG.

Os dados referentes à precipitação, à insolação e à temperatura, observados durante a realização do ensaio, foram obtidos na Estação Meteorológica do INMET de Montes Claros, localizada a aproximadamente $1,5 \mathrm{~km}$ da área experimental.
Os experimentos foram dispostos em blocos casualizados, com quatro repetições, em esquema fatorial $2 \times 3+1$, sendo o fator composto por dois tipos de sombreamento: a $30 \%$ e a $50 \%$, combinados com três épocas de entrada pós-início do perfilhamento na sombra com 07, 14 e 21 dias, mais uma testemunha adicional mantida a pleno sol.

As mudas de A. gayanus cv. 'Planaltina' e P. maximum cv. 'Tanzânia' foram pré-cultivadas em bandejas de isopor, usadas para a produção de mudas de hortaliças, contendo substrato comercial, mantidas em casa de vegetação, com irrigação de duas vezes ao dia, por aspersão. Após 35 dias, com as mudas apresentando, aproximadamente, $10 \mathrm{~cm}$ de altura, ocorreu o transplantio para os vasos com volume de 12 litros, contendo substrato preparado nas proporções de 3:1:1 de solo, areia e esterco bovino curtido, respectivamente, e 50g/vaso de Super Simples. O solo utilizado para preparo do substrato é um Argissolo Vermelho, cujos atributos determinados pela análise química e granulométrica apresentaram os seguintes resultados: $\mathrm{pH}\left(\mathrm{H}_{2} \mathrm{O}\right)=5,2 ; \mathrm{Ca}^{2+}=1,10 \mathrm{cmol}_{\mathrm{c}} \mathrm{dm}^{-3}$; $\mathrm{Mg}=0,5 \mathrm{cmol}_{\mathrm{c}} \mathrm{dm}^{-3} ; \mathrm{P}$ Mehlich=2,18mg kg-1; Prem $=13,76 \mathrm{mg} \mathrm{L}^{-1} ; \mathrm{K}=80 \mathrm{mg} \mathrm{kg}^{-1}$; soma de bases $=1,81 \mathrm{cmol}_{\mathrm{c}} \mathrm{dm}^{-3}$; saturação por bases $=27 \%$; matéria orgânica $=1,88 \mathrm{dag} \mathrm{kg}^{-1}$; areia grossa=4,10dag $\mathrm{kg}^{-1}$; areia fina $=29,90 \mathrm{dag}_{\mathrm{kg}^{-1}}$; silte $=22,0 \mathrm{dag} \mathrm{kg}^{-1}$; argila $=44,0 \mathrm{dag} \mathrm{\textrm {kg } ^ { - 1 }}$. No transplante, foram colocadas quatro mudas de cada espécie, por vaso, equidistantes uma da outra, totalizando 56 vasos por espécie. Após 27 dias, no início do perfilhamento, realizou-se uma adubação com $5 \mathrm{~g} /$ vaso de sulfato de amônio e controle manual de plantas daninhas.

Após 27 dias, semanalmente, eram inseridos quatro vasos debaixo do sombrite, referentes às épocas de entrada na sombra de 07, 14 e 21 dias após o início do perfilhamento, deixando quatro vasos de cada espécie sob sol pleno por todo o período de realização do ensaio. Os sombrites utilizados foram telas de polipropileno com $30 \%$ e $50 \%$ de sombreamento, previamente montados sobre estrutura de sustentação, feita com estacas de madeira de 2,5m de altura, mantendo-se o cuidado de cobrir totalmente as plantas por todo o período do dia, independente da posição do sol.

Decorridos 28 dias da inserção de todas as plantas na sombra, em seus respectivos tratamentos, coletaram-se 10 folhas totalmente expandidas de $\boldsymbol{A}$. gayanus cv. 'Planaltina' e P. maximum cv. 'Tanzânia', por parcela (vaso), as quais foram posteriormente picadas em fragmentos em torno $0,5 \mathrm{~cm}$, para determinação dos teores de clorofila, segundo ARNON (1949). Do material fragmentado, colocou-se $0,5 \mathrm{~g}$ de 
massa fresca em tubos de ensaio com $10 \mathrm{~mL}$ de acetona $80 \%(\mathrm{v} / \mathrm{v})$ em água. Esses foram tampados e deixados em câmara fria protegida da luz por 24 horas. Após esse período, os extratos foram filtrados e colocados nas cubetas do espectrofotômetro, previamente calibrado com acetona $80 \%$, utilizada na extração das clorofilas. As leituras foram realizadas na seguinte ordem: para clorofila $a$, com comprimento de onda de $663 \mathrm{~nm}$ e depois clorofila $b$, com comprimento de onda de $645 \mathrm{~nm}$. Após as leituras, os resultados foram lançados nas equações propostas por WHITHAM, BLAYDES \& DEVLIN (1971) para a estimativa dos teores de clorofila $a$ e $b$, expressos em mg de clorofila/ grama de massa fresca $\left(\mathrm{mg} \mathrm{gmf}^{-1}\right)$. Sendo a clorofila $a=(0,0127 \times A b s a 663-0,00269 \times A b s b 645) \mathrm{e}$, a clorofila $b=(0,0229 \times A b s b 645-0,00468 \times A b s a 663)$.

Após a coleta de material para análise das clorofilas, as plantas foram cortadas, deixando no vaso $20 \mathrm{~cm}$ de altura para rebrota. A forragem cortada foi comparada visualmente a vista desarmada quanto à intensidade da cor verde nos tecidos foliares. Em seguida, o material foi triturado e acondicionado em sacos de papel previamente identificados e, posteriormente, pesados para a obtenção da massa fresca $(\mathrm{MF})$ e levadas à estufa a $55^{\circ} \mathrm{C}$ com ventilação forçada, até atingirem peso constante para a obtenção da massa seca, segundo metodologia descrita em SILVA \& QUEIROZ (2002). O mesmo procedimento descrito anteriormente foi realizado para os vasos mantidos a pleno sol, para as duas espécies.

Nas amostras devidamente processadas da parte aérea (folhas + colmos) de A. gayanus cv. 'Planaltina' e $\boldsymbol{P}$. maximum cv. 'Tanzânia', foram realizadas determinações de matéria seca (MS), de fibra em detergente neutro (FDN), de fibra em detergente ácido (FDA), de proteína bruta (PB), de cinzas (MM), segundo metodologia descrita por SILVA\& QUEIROZ (2002). As variáveis quantitativas foram submetidas à análise de variância pelo Teste $\mathrm{Fe}$, quando pertinente, as suas médias foram comparadas pelo teste de Scott knott a 5\% de probabilidade de erro, pelo programa de análises estatíticas SAEG 9.1.

\section{RESULTADOS E DISCUSSÃO}

As concentrações de clorofila $b$ encontradas nas folhas de $\boldsymbol{P}$. maximum cv. 'Tanzânia' e de A. gayanus cv. 'Planaltina', cultivadas à sombra e ao pleno sol foram similares $(\mathrm{P}>0,05)$, não sendo detectado efeito das épocas de disposição das plantas na sombra e da interação entre os fatores (Tabela 1).

Para a clorofila $a$, maiores $(\mathrm{P}<0,05)$ teores da substância foram encontrados em plantas sombreadas das duas espécies forrageiras, quando comparadas às mantidas a pleno sol (Tabela 1). Plantas que passaram maior tempo sob a sombra, correspondente aos vasos de sete dias após o início do perfilhamento, apresentaram maior teor de clorofila em maior sombreamento (50\%), quando comparado com os valores encontrados sob 30\% de sombra (Tabela 1). Plantas de $\boldsymbol{P}$. maximum cv. 'Tanzânia', dispostas na sombra aos 14 e 21 dias após o perfilhamento, apresentaram maior concentração de clorofila $a$, quando cultivadas a $30 \%$ de sombra.

O maior acúmulo de clorofila $a$ pode ser uma resposta dos vegetais para melhorar o aproveitamento da luz em ambientes sombreados. Na literatura, há relatos de maior concentração de clorofila por centro de reação nos cloroplastos em folhas expostas à sombra, com razão entre a clorofila $b$ e $a$ mais elevada, quando comparada a folhas a pleno sol (TAIZ \& ZEIGER, 2009). A relação entre clorofila $b$ e $a$ apresenta valores menores em plantas expostas à sombra, quando comparadas às plantas crescidas no pleno sol, tanto para P. maximum cv. 'Tanzânia' quanto para A. gayanus cv. 'Planaltina'.

SOARES et al. (2009) consideram esse resultado como aumento na concentração de nitrogênio, pois a planta reduz sua matéria seca para acumular componentes, como água, minerais e produzir clorofila $a$. As maiores concentrações de clorofila $a$ podem explicar a coloração verde mais intensa, observada em plantas de A. gayanus sombreadas, quando comparadas aos indivíduos mantidos a pleno sol.

As produções de massas fresca e seca da parte aérea do A. gayanus cv. 'Planaltina' foram maiores $(\mathrm{P}<0,05)$ nos ambientes com 30 e $50 \%$ de sombra, quando comparadas às plantas mantidas a pleno sol (Tabela 2). O mesmo resultado foi encontrado por CASTRO et al. (1999) e CARVALHO et al. (1997), que obtiveram as produções dessa forrageira decrescidas com o sombreamento. Esse decréscimo na produtividade é devido à radiação luminosa do ambiente sombreado ser inferior à correspondente ao ponto de compensação lumínico característico da espécie.

A dependência de fatores climáticos como temperatura e umidade são características importantes para o bom desenvolvimento das plantas de metabolismo C4. As árvores exercem efeito direto sobre essas variáveis, porém não foi encontrada diferença produtiva para uma pastagem sombreada de aroeira para a pastagem em pleno sol, mesmo com temperaturas sob as árvores menores $2,3^{\circ} \mathrm{C}$ em média do que aqueles em pleno sol (SOUSA et al., 2010). 
Tabela 1 - Teores de clorofila $\boldsymbol{a}$ e $\boldsymbol{b}\left(\mathrm{mg} \mathrm{gmf}^{-1}\right)$ encontrados em folhas de Andropogon gayanus cv. 'Planaltina' e Panicum maximum cv. 'Tanzânia', cultivadas à sombra e a pleno sol, aos 75 dias após o transplantio.

\begin{tabular}{|c|c|c|c|}
\hline \multicolumn{4}{|c|}{ Andropogon gayanus cv. 'Planaltina' } \\
\hline \multicolumn{4}{|c|}{ 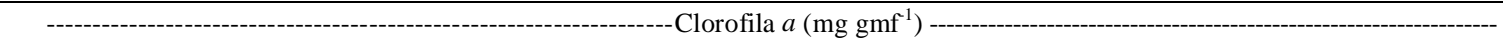 } \\
\hline Época de entrada na sombra (dias) & $30 \%$ & $50 \%$ & Pleno sol \\
\hline 7 & $0,015 \mathrm{~B}$ & $0,018 \mathrm{~A}$ & \\
\hline 14 & $0,013 \mathrm{~B}$ & $0,023 \mathrm{~A}$ & \\
\hline 21 & $0,013 \mathrm{~B}$ & $0,024 \mathrm{~A}$ & \\
\hline Média & $0,014 \mathrm{~B}$ & $0,022 \mathrm{~A}$ & \\
\hline Média & \multicolumn{2}{|c|}{$0,018 \mathrm{~A}$} & 0,012 B \\
\hline \multicolumn{4}{|l|}{----- } \\
\hline 7 & 0,009 & 0,013 & \\
\hline 14 & 0,017 & 0,017 & \\
\hline 21 & 0,013 & 0,015 & \\
\hline Média & 0,013 & 0,015 & 0,012 \\
\hline \multicolumn{4}{|c|}{ 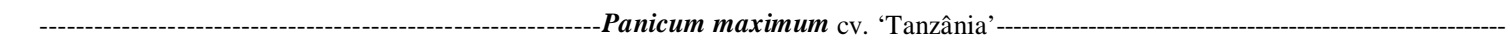 } \\
\hline Época de entrada na sombra (dias) & $30 \%$ & $50 \%$ & Pleno sol \\
\hline 7 & $0,007 \mathrm{~B}$ & $0,010 \mathrm{~A}$ & \\
\hline 14 & $0,012 \mathrm{~A}$ & $0,009 \mathrm{~B}$ & \\
\hline 21 & $0,012 \mathrm{~A}$ & $0,011 \mathrm{~B}$ & \\
\hline Média & $0,010 \mathrm{~A}$ & $0,010 \mathrm{~A}$ & \\
\hline Média & \multicolumn{2}{|c|}{$0,01 \mathrm{~A}$} & $0,005 \mathrm{~B}$ \\
\hline--- & ----- & 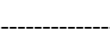 & 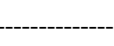 \\
\hline 7 & 0,009 & 0,016 & 0,019 \\
\hline 14 & 0,014 & 0,013 & \\
\hline 21 & 0,008 & 0,016 & \\
\hline Média & 0,010 & 0,015 & \\
\hline
\end{tabular}

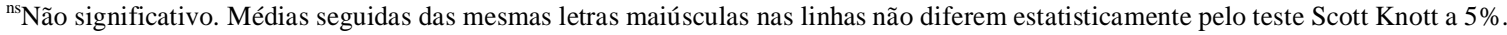

As massas fresca e seca de $\boldsymbol{P}$. maximum $\mathrm{cv}$. 'Tanzânia' não foram alteradas $(\mathrm{P}>0,05)$ pela época de entrada das plantas na sombra e nem pela interação entre ambiente versus entrada na sombra, assim como foi similar à produção obtida nos diferentes graus de sombreamento (Tabela 2). Esse resultado é semelhante ao encontrado por CASTRO et al. (2009), trabalhando com Brachiaria decumbens.

A redução da radiação fotossinteticamente ativa pode diminuir as taxas fotossintéticas de forrageiras que têm metabolismo C4 (DIAS-FILHO, 2002), visto que essa característica tem sido observada quando o sombreamento supera os níveis de $50 \%$ da radiação a sol pleno (PACIULLO et al., 2007; GUENNI et al., 2008). Assim, sombreamentos entre 30\% e 50\% podem não afetar o crescimento de gramíneas que sejam moderadamente tolerantes ao sombreamento (ANDRADE et al., 2004; PACIULLO et al., 2008).

Sabe-se que a cultivar 'Tanzânia' apresenta tolerância média ao déficit de luminosidade (SHELTON et al., 1987; CASTRO et al., 1999). Plantas sob luminosidade reduzida têm desenvolvimento mais lento e menor perda de água pelos seus tecidos, que ficam mais tenros e suculentos, caracterizando menor teor de matéria seca da planta (VOLENEC \& NELSON, 2003). Porém ocorrem modificações morfofisiológicas, tais como aumentos de área foliar e alongamento foliar, possibilitando a conservação da produtividade (GUENNI et al., 2008).

As variáveis bromatológicas não apresentaram diferenças $(\mathrm{P}>0,05)$, em função dos níveis de sombreamento e da época de entrada na sombra (Tabela 3) para o A. gayanus cv. 'Planaltina' e Panicum maximun cv. 'Tanzânia', apresentando características semelhantes às plantas deixadas a pleno sol. Tal resultado também foi encontrado por LACERDA et al. (2009), trabalhando com idades de rebrota diferentes em sistema silvipastoril.

No presente estudo, obtiveram-se teores discretamente menores de massa seca para $50 \%$ de 
Tabela 2 - Massa seca e fresca da parte aérea (colmos e folhas) por parcela de Andropogon gayanus cv. 'Planaltina' e Panicum maximum cv. 'Tanzânia', cultivado à sombra e a pleno sol, aos 75 dias após o transplantio.

\begin{tabular}{|c|c|c|c|}
\hline \multicolumn{4}{|c|}{ Andropogon gayanus cv. 'Planaltina' } \\
\hline 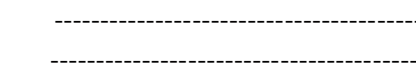 & ------------' n & - n & - n \\
\hline Época de entrada na sombra (dias) & $30 \%$ & $50 \%$ & Pleno sol \\
\hline 7 & $135,61 \mathrm{~A}$ & $92,25 \mathrm{~B}$ & \\
\hline 14 & $115,57 \mathrm{~A}$ & $106,27 \mathrm{~B}$ & \\
\hline 21 & $135,36 \mathrm{~A}$ & $84,45 \mathrm{~B}$ & \\
\hline Média & $128,85 \mathrm{~A}$ & $94,32 \mathrm{~B}$ & \\
\hline $\begin{array}{l}111,59 \mathrm{~A} \\
\text { Seca (g vaso }\end{array}$ & \multicolumn{2}{|c|}{$111,59 \mathrm{~A}$} & $53,58 \mathrm{~B}$ \\
\hline 7 & 35,89 & 23,16 & \\
\hline 14 & 28,88 & 22,99 & \\
\hline 21 & 31,78 & 21,01 & \\
\hline Média & $32,18 \mathrm{~A}$ & $22,39 \mathrm{~B}$ & \\
\hline Média & & & $14,88 \mathrm{~B}$ \\
\hline \multicolumn{4}{|c|}{$\begin{array}{c}27,29 \mathrm{~A} \\
\text { Panicum maximum } \mathrm{cv} . \text { 'Ta }\end{array}$} \\
\hline Época de entrada na sombra (dias) & $30 \%$ & $50 \%$ & Pleno sol \\
\hline 7 & 121,66 & 121,17 & \\
\hline 14 & 111,93 & 99,51 & \\
\hline 21 & 102,60 & 104,12 & \\
\hline Média & 112,06 & 108,27 & \\
\hline Média & \multicolumn{2}{|c|}{$110,165 \mathrm{~A}$} & $54,63 \mathrm{~B}$ \\
\hline 7 & 32,00 & 33,27 & \\
\hline 14 & 29,22 & 25,25 & \\
\hline 21 & 27,41 & 25,82 & \\
\hline Média & 29,54 & 28,11 & \\
\hline Média & & & $14,51 \mathrm{~B}$ \\
\hline
\end{tabular}

${ }^{n s}$ Não significativo. Médias seguidas das mesmas letras maiúsculas nas linhas não diferem estatisticamente pelo teste Scott Knott a 5\%.

sombra. O sombreamento reduziu significativamente o teor de matéria seca da B. brizantha cv. 'Marandu', porém, segundo CARVALHO et al. (1995), que trabalharam com cinco gramíneas forrageiras tropicais sob a copa de angico-vermelho, a diminuição da massa seca estava ligada a maiores proporções de folhas verdes dessas forragens nas áreas sombreadas, o que representa uma vantagem do ponto de vista do pastejo, uma vez que as folhas geralmente têm melhor valor nutritivo que os colmos.

CARVALHO et al. (1997), ao trabalharem com seis gramíneas tropicais cultivadas em sub-bosque de angico-vermelho (A. macrocarpa), verificaram que a produção de proteína bruta da $\boldsymbol{B}$. brizantha $\mathrm{cv}$. 'Marandu' foi $47 \%$ maior quando essa estava sombreada. Assim como PACIULLO et al. (2007), que obtiveram maior teor de proteína em Brachiaria decumbens, cultivada em áreas sombreadas em relação às áreas a pleno sol, sendo este fato justificado por
WILSON (1996) como decorrente de aumento na degradação da matéria orgânica e da maior reciclagem de nitrogênio no solo em áreas sombreadas.

Quanto ao teor de FDN na planta, não houve diferença entre os tratamentos, assim como os demais componentes bromatológicos. Esse resultado é semelhante ao encontrado por CARVALHO et al. (2002), que não verificaram efeito do sombreamento sobre o teor de FDN na parte aérea de gramíneas tropicais dos gêneros Brachiaria, Panicum e Cynodon, entretanto, o sombreamento influenciou no desenvolvimento vegetativo dessas gramíneas, retardando o florescimento, fato positivo para o manejo dessas forrageiras.

O sombreamento pode reduzir a disponibilidade de fotoassimilados utilizados para o desenvolvimento da parede celular secundária, contribuindo para a redução dos teores de fibra e aumentando a digestibilidade (KEPHART \&BUXTON, 1993). 
Tabela 3 - Aspectos bromatológicos do capim Andropogon gayanus cv. 'Planaltina' e Panicum maximum cv. 'Tanzânia', cultivado à sombra e a pleno sol, aos 75 dias após o transplantio, nas diversas épocas de entrada na sombra (EES).

\begin{tabular}{|c|c|c|c|c|c|c|c|}
\hline \multicolumn{4}{|c|}{ Andropogon gayanus cv. 'Planaltina' } & \multicolumn{4}{|c|}{ Panicum maximum cv. 'Tanzânia' } \\
\hline \multicolumn{8}{|c|}{ 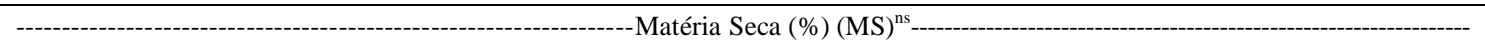 } \\
\hline EES (dias) & $30 \%$ & $50 \%$ & Pleno sol & EES (dias) & $30 \%$ & $50 \%$ & Pleno sol \\
\hline 7 & 94,88 & 92,67 & \multirow{4}{*}{93,52} & 7 & 94,54 & 94,35 & \multirow{4}{*}{96,14} \\
\hline 14 & 92,83 & 92,47 & & 14 & 93,45 & 94,81 & \\
\hline 21 & 91,76 & 93,13 & & 21 & 92,76 & 93,13 & \\
\hline Média & 93,16 & 92,76 & & Média & 93,58 & 94,09 & \\
\hline & - & - & --------. & \%) $)^{\mathrm{ns}}$ & & & --- \\
\hline 7 & 4,89 & 5,03 & \multirow{4}{*}{5,77} & 7 & 8,44 & 9,17 & \multirow{4}{*}{10,2} \\
\hline 14 & 4,94 & 5,2 & & 14 & 9,24 & 8,51 & \\
\hline 21 & 5,44 & 5,76 & & 21 & 8,96 & 7,9 & \\
\hline Média & 5,09 & 5,33 & & Média & 8,88 & 8,53 & \\
\hline---- & & - n--- & ---Proteír & $(\%)(\mathrm{PB})^{\mathrm{ns}}$ & & & \\
\hline 7 & 5,74 & 5,38 & \multirow{4}{*}{6,1} & 7 & 5,78 & 4,59 & \multirow{4}{*}{5,36} \\
\hline 14 & 5,3 & 5,81 & & 14 & 6,02 & 4,66 & \\
\hline 21 & 5,49 & 7,01 & & 21 & 6,94 & 5,81 & \\
\hline Média & 5,51 & 6,07 & & Média & 6,25 & 5,02 & \\
\hline 7 & 69,13 & 67,37 & \multirow{4}{*}{69,83} & 7 & 70,6 & 69,18 & \multirow{4}{*}{71,68} \\
\hline 14 & 69,89 & 68,27 & & 14 & 71,02 & 69,53 & \\
\hline 21 & 69,6 & 68,68 & & 21 & 69,77 & 70,21 & \\
\hline Média & 69,54 & 68,11 & & Média & 70,46 & 69,64 & \\
\hline-- & & --.-- & ----- & 6) ${ }^{\mathrm{ns}}$ & 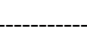 & & ------ \\
\hline 7 & 35,39 & 34,6 & \multirow{4}{*}{40,12} & 7 & 37,49 & 40,77 & \multirow{4}{*}{38,84} \\
\hline 14 & 39,75 & 35,68 & & 14 & 34,33 & 37,09 & \\
\hline 21 & 31,7 & 32,53 & & 21 & 38,91 & 46,5 & \\
\hline Média & 35,61 & 34,27 & & Média & 36,91 & 41,45 & \\
\hline
\end{tabular}

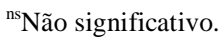

\section{CONCLUSÃO}

A produção de A. gayanus cv. 'Planaltina' e P. maximum cv. 'Tanzânia' é maior em ambientes sombreados do que a pleno sol. As duas forrageiras possuem alterações fisiológicas nas folhas, com incrementos nos teores de clorofila $a$, não havendo variações na composição de Matéria Seca, proteína bruta, cinzas, FDN e FDA da forragem produzida.

\section{REFERÊNCIAS}

ANDRADE, C.M.S. et al. Crescimento de gramíneas e leguminosas forrageiras tropicais sob sombreamento. Pesquisa Agropecuária Brasileira, v.39, n.3, p.263-270, 2004. Disponivel em: <http:/ /dx.doi.org/10.1590/S0100-204X2004000300009>. Acesso em: 13 fev. 2011. doi: 10.1590/S0100-204X2004000300009.

ANDRADE, R.P. Tecnologia de produção de sementes de espécies do genêro Brachiaria. In: SIMPÓSIO SOBRE MANEJO DA PASTAGEM, 11., 1994, Piracicaba, SP. Anais... Piracicaba: Fundação de Estudos Agrários Luiz de Queiroz, 1994. p.49-71.
ARNON, D.I. Copper enzymes in isolated chloroplasts. Polyphenoloxidase in Beta vulgaris. Plant Physiology, v.24, n.1, p.1-15, 1949. Disponível em: <http://www.ncbi.nlm.nih.gov/ pmc/articles/PMC437905/pdf/plntphys00263-0011.pdf >. Acesso em: 30 jan. 2011.

CAMPOS, N.R. et al. Características Morfogênicas e Estruturais da Brachiaria decumbens em sistema silvipastoril e cultivo exclusivo. Revista Brasileira de Biociências, v.5, sup1.2, p.819-821, 2007. Disponível em: <http://www6.ufrgs.br/seerbio/ ojs/index.php/rbb/article/viewFile/689/580>. Acesso em: 30 jan. 2011.

CARVALHO, M.M. et al. Início de florescimento, produção e valor nutritivo de gramíneas forrageiras tropicais sob condição de sombreamento natural. Pesquisa Agropecuária Brasileira, v.37, n.5, p.717-722, 2002. Disponível em: <http:/ /dx.doi.org/10.1590/S0100-204X2002000500018>. Acesso em: 2 fev. 2011. doi: 10.1590/S0100-204X2002000500018.

CARVALHO, M.M. et al. Produção de matéria seca e composição química da forragem de seis gramíneas tropicais estabelecidas em um sub-bosque de angico vermelho. Revista Brasileira de Zootecnia, v.26, n.2, p.213-218, 1997.

Ciência Rural, v.43, n.2, fev, 2013. 
CARVALHO, M.M. et al. Crescimento inicial de cinco gramíneas tropicais em um sub-bosque de angico vermelho (Anadenanthera macrocarpa Benth.). Pasturas Tropicales, v.17, n.1, p.2430, 1995. Disponível em: <http://ciat-library.ciat.cgiar.org/ Articulos_Ciat/Vol17_rev1_a\%C3\%B1095_art6.pdf >. Acesso em: 14 fev. 2011.

CASTRO, C.R.T. et al. Características agronômicas, massa de forragem e valor nutritivo de Brachiaria decumbens em Sistema silvipastoril. Pesquisa Florestal Brasileira, v.60, n. esp., p.19-25, 2009. Disponível em: 〈http://www.cnpf.embrapa.br/ pfb/index.php/pfb/article/view/42/47>. Acesso em: 10 fev. 2011. doi: 10.4336/2009.pfb.60.19.

CASTRO, C.R.T. et al. Produção forrageira de gramíneas cultivadas sob luminosidade reduzida. Revista Brasileira de Zootecnia, v.28, n.5, p.919-927, 1999. Disponível em: <http:/ /b pa.cnpgc.embrapa.br/material/Literatura/ producaoforrageirasobluminosidad\%20reduzida.pdf $>$. Acesso em: 9 fev. 2011.

DIAS-FILHO, M.B. Photosynthetic light response of the C4 grasses Brachiaria brizantha and $\boldsymbol{B}$. humidicula under shade. Scientia Agricola, v.59, n.1, p.65-68, 2002. Disponível em: <http://dx.doi.org/10.1590/S0103-90162002000100009>. Acesso em: 1 fev. 2011. doi: 10.1590/S010390162002000100009 .

DIAS-FILHO, M. Growth and biomass allocation of the C4 grasses Brachiaria brizantha and $\boldsymbol{B}$. humidicola under shade. Pesquisa Agropecuária Brasileira, v.35, n.12, p.2335-2341, 2000. Disponível em: <http://dx.doi.org/10.1590/S0100204X2000001200003>. Acesso em: 21 jan. 2011. doi: 10.1590/S0100-204X2000001200003.

GUENNI, O. et al. Growth responses of three Brachiaria species to light intensity and nitrogen supply. Tropical Grasslands, v.42, p.75-87, 2008. Disponível em: <http://www.ufrrj.br/ posgrad/cpz/selecao_2011/2001-2/referencias/doutorado/ forrageiras/Referencia3.pdf $>$. Acesso em: 24 mar. 2011.

MACEDO, M.C.M.; ZIMMER, A.H. Sistemas integrados de lavoura - pecuária na região dos Cerrados do Brasil. In: SIMPÓSIO INTERNACIONAL EM INTEGRAÇÃO LAVOURA - PECUÁRIA, 2007, Curitiba, PR. Anais... Curitiba: UFPR: UFRGS: Ohio State University, 2007. 24p. CD-ROM.

PACIULLO, D.S.C. et al. Características produtivas e nutricionais do pasto em sistema agrossilvipastoril, conforme a distância das árvores. Pesquisa Agropecuária Brasileira, v.46, n.10, p.1176-1183, 2011. Disponível em: <http://
dx.doi.org/10.1590/S0100-204X2011001000009>. Acesso em: 5 set. 2012. doi: 10.1590/S0100-204X2011001000009.

PACIULLO, D.S.C. et al. Crescimento de capim-braquiária influenciado pelo grau de sombreamento e pela estação do ano. Pesquisa Agropecuária Brasileira, v.43, p.917-923, 2008. Disponível em: <http://dx.doi.org/10.1590/S0100204X2008000700017>. Acesso em: 22 jan. 2011. doi: 10.1590/S0100-204X2008000700017.

PACIULLO, D.S.C. et al. Morfofisiologia e valor nutritivo do capim-braquiária sob sombreamento natural e a sol pleno. Pesquisa Agropecuária Brasileira, v.42, n.4, p.573-579, 2007. Disponível em: <http://dx.doi.org/10.1590/S0100204X2007000400016>. Acesso em: 20 jan. 2011. doi: 10.1590/S0100-204X2007000400016.

SILVA, D.J.; QUEIROZ, A.C. Análise de alimentos: métodos químicos e biológicos. Viçosa: UFV, 2002. 235p.

SOARES, A.B. et al. Influência da luminosidade no comportamento de onze espécies forrageiras perenes de verão. Revista Brasileira de Zootecnia, v.38, n.3, p.443-451, 2009. Disponível em: <http://dx.doi.org/10.1590/S151635982009000300007>. Acesso em: 29 jan. 2011. doi: 10.1590/ S1516-35982009000300007.

SOUSA, L.F. et al. Nutritional evaluation of "Braquiarão" grass in association with "Aroeira" trees in a silvopastoral system. Agroforest Syst, v.79, p.189-199, 2010. Disponível em: <http:/ /rd.springer.com/article/10.1007/s10457-010-9297-8>. Acesso em: 3 fev. 2011. doi: 10.1007/s10457-010-9297-8.

SHELTON, H.M. et al. Pastures in the plantations of Asia and Pacific: performance and prospects. Tropical Grasslands, v.21, n.4, p.159-168, 1987.

TAIZ, L.; ZEIGER, E. Fisiologia vegetal. 2.ed. Porto Alegre: Artmed, 2009. 819p.

VOLENEC, J.J.; NELSON, C.J. Environmental aspects of forage management. In: BARNES, R.F. et al. (Eds.). Forages: an introduction to grassland agriculture. 6.ed. Ames: Blackwell, 2003. p.99-124.

WHITHAM, F.H. et al. Experiments in plant physiology. New York: D. Van Nostrand, 1971. 245p.

WILSON, J.R. Shade-stimulated growth and nitrogen uptake by pasture grasses in a subtropical environment. Australian Journal of Agricultural Research, v.47, n.7, p.1075-1093, 1996. Disponível em: <http://www.publish.csiro.au/ ?act=view_file\&file_id=AR9961075.pdf $>$. Acesso em: 23 jan. 2011. 